\title{
Sürtünme Kaynak Yöntemi Uygulamalarında Ahşap Esaslı Malzemelerinin Kullanımının İncelenmesi
}

\author{
Mustafa ZOR \\ Zonguldak Bülent Ecevit Üniversitesi, Çaycuma Meslek Yüksekokulu, Tasarım Bölümü,67900, ZONGULDAK
}

Öz

Tutkal, metal veya herhangi bir bağlayıcı kullanmadan yeni, çevre dostu ürünler elde etmek için iki parçayı mekanik olarak birbirine bağlama tekniği olan sürtünme kaynak uygulaması yeni bir yöntem olarak ortaya çıkmaktadır. Son zamanlarda masif ahşaba uygulanan bu yöntem, kaynak parametreleri üzerine ahşabın özelliklerinin değişimini araştırmak için kullanılmaktadır. Bu yöntem gerçekten iyi sonuçlar verirse, orman ürünleri endüstrisinin geleceğini önemli ölçüde değiştirecektir. Ahşap malzemenin mekanik anlamda birleşimindeki bu yeni metod, ileri teknoloji sayesinde birçok mühendislik uygulamalarında kullanılabilir.

Anahtar Kelimeler: Sürtünme Kaynağı Metodu, Birleştirme, Ahşap Malzeme.

\section{Investigation of the Use of Wood Based Materials in Friction Welding Method Applications}

\begin{abstract}
The friction welding procedure, which is the method of mechanically connecting two parts together to obtain new, environmentally friendly products without using glue, metal or any fasteners, has revealed a new method. This method, which has recently been applied to the solid wood, is used to investigate the variation of wood properties on the welding parameters. If this method actually produces good results, the future of forest products industry will change significantly. This new method of combining solid wood with mechanical means can be used in many engineering applications due to advanced technology.
\end{abstract}

Keywords: Friction Welding Method, Joining, Wooden Material. 


\section{Sürtünme Kaynak Yöntemi Uygulamalarına Giriş}

Kaynak, metallerin moleküler seviyede birleştirilme işlemi olarak ifade edilmektedir. Bir kaynak iki veya daha fazla metal parçaların gücünü arttıran kaynakla birleştirilmiş metal parçası arasında homojen bir bağ vardır. Kaynak, uygun bir ısı ve/veya basınç uygulaması ile iki veya daha fazla parçanın temas yüzeylerinde kalıcı olarak birleştirildiği bir işlemdir. Çoğunlukla bu işleme, birleşmeyi kolaylaştırmak için bir dolgu maddesi eklenir. Kaynak işlemi ile birleştirilen parçalara kaynaklı parçalar denir. Kaynak işlemi, temel olarak metal parçalarda ve alaşımlarında kullanılmaktadır.

Kaynak işlemleri iki ana gruba ayrılır:

- Füzyon kaynağı: Bu işlemde, ana metal 1sı yoluyla eritilir. Çoğunlukla füzyon kaynak işlemlerinde, işlemi kolaylaştırmak ve birleşim yerine ağırlık ve kuvvet sağlamak için eriyik havuza bir dolgu metali eklenir. Yaygın olarak kullanılan füzyon kaynak işlemleri şunlardır: ark kaynağı, direnç kaynağı, oksi yakıt kaynağı, elektron 1şını kaynağı ve lazer ışını kaynağı.

- Katı hal kaynağı: Bu işlemde parçaların birleştirilmesi tek başına basınç uygulanması veya bir ısı ve basınç kombinasyonu ile gerçekleştirilir. Dolgu metali kullanılmaz. Yaygın olarak kullanılan katı hal kaynak işlemleri şunlardır: difüzyon kaynağı, sürtünme kaynağı, ultrasonik kaynağı (URL-1).

Sürtünme kaynağında katı hal kaynak işlemi, sürtünme yüzeyleri arasında mekanik olarak indüklenen dönme hareketinden elde edilen 1sı kullanılarak elde edilir. İki parçanın ara yüzündeki sıcaklık yeterince yüksek olduğunda, dönme hareketi durdurulur ve artan eksenel kuvvet uygulanır. Bu iki parçayı birbirine bağlar. Dönme kuvveti, güçlü bir motor veya bir volan vasıtasıyla sağlanır. İkinci durumda, işlem atalet kaynağı olarak adlandirılabilir (URL-1).

\section{Kaynak Birleștirme Tipleri}

Genel olarak kaynak işlemlerinde kullanılan beş yaygın kaynak bağlantı türü vardır: köşe bağlantı tipi, kenar bağlantı tipi, bindirme kaynak yöntemi tipi, “T” bağlantı tipi ve alın bağlantı tipi (Şekil 1.) olarak sıralanır.

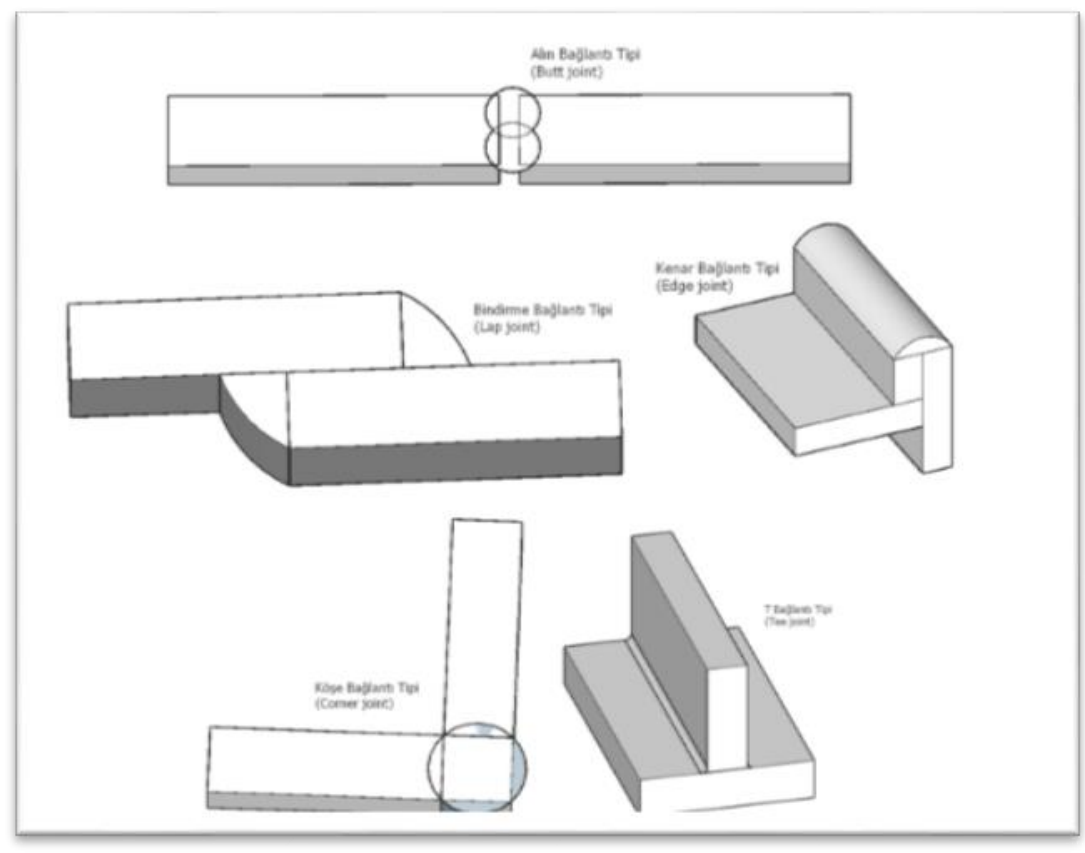

Şekil 1. Kaynak birleştirme tipleri 


\section{Kaynak Birleştirme Yönteminin Avantajları}

- Kaynak yapılan yapılar perçinlenmiş yapılara kıyasla genellikle hafiftir. Bunun nedeni, kaynakta köşebentlerin veya diğer bağlantı bileşenlerinin kullanılmamasıdır.

- Kaynaklı bağlantılar, perçinlenmiş bağlantılar olması durumunda tahmin edilenden daha yüksek verimlilik sağlamaktadır.

- Mevcut yapılarda kolayca değişiklik ve ilaveler yapılabilmektedir.

- Kaynaklı yapılar görünüşte pürüzsüzdür, dolayısıyla göze hoş görünmektedir.

- Kaynaklı bir bağlantı, büyük bir güce sahiptir. Çoğu zaman kaynaklı bir bağlantı ana metalin kendi gücüne sahip olmaktadır.

- Bir yapının herhangi bir bölümünü herhangi bir noktadan kaynaklamak kolaydır. Ancak perçinleme için yeterli alana sahip olması gerekmektedir. Kaynaklı bağlantıların yapılması işlemi perçinlenmiş bağlantılardan daha az zaman almaktadır.

- Kaynak işlemi, birleştirmelerde çok güçlü bağlantılar sağlamaktadır. Parçalar kolayca bükülememektedir. Bu, rijit çerçeveler sağlamadaki modern eğilim ile aynı doğrultudadır.

- Kaynaklı bağlantılardaki gergi elemanları, perçinli bağlantılarda olduğu gibi zayıf dayanım göstermemektedir.

\section{Kaynak Birleştirme Yönteminin Dezavantajları}

- Kaynak parametrelerini kullanarak kaynak birleştirmeleri yapmak için çok yetenekli bir emek ve deneyim (ve kontrol) gerekmektedir.

- Üretim sırasında kaynak işleminde dengesiz bir ısıtma ve soğutma olduğundan, parçalar çarpılabilir veya ek gerilmeler oluşabilir.

- Üretim çerçevesinde genişleme ve daralma için kesin bir bilgi bulunmadığından, içinde çatlakların oluşması ihtimali vardır.

- Kaynak işindeki kusurların incelenmesi perçinleme işinden daha zordur (URL-2).

$\mathrm{Bu}$ yöntemin uygulama alanları olarak otomobil endüstrileri, yüksek basınçlı kapların imalatı, ağır mekanik ve hidrolik preslerin çerçeveleri, haddehane çerçeveleri vb. sıralanabilir. 2000 yılından bu yana, İ́sviçre Federal Enstitüsü'nün Lozan'daki ahşap konstrüksiyon teknoloji laboratuvarı (EPFL), sürtünme kaynağının oduna uygulanmasını araştırmaktadır.

\section{Ahşap Malzemenin Kaynak Uygulamalarında Kullanımı}

Doğal bir polimerik malzeme olan ahşap, dünyadaki en bol miktarda bulunan yenilenebilir bir materyaldir. Bu durum, ağacın farklı şekle ve çapa sahip olması nedeniyle, boyutlarının nispeten sınırlı olduğu gerçeğini gizleyememektedir. Daha karmaşık yapılar elde edebilmek için odun parçaları arasında etkili bir takım bağlantılar gerekli olmaktadır. Örneğin, ahşap endüstrisinde iki bağlantı türü yaygın olarak kullanılır. Bunlardan ilki vidalar, dişli çubuklar ya da çiviler gibi metal bağlantılar, diğer taraftan güçlü anatomik bağlantılar olarak ifade edilen kimyasal yapıştırıcılar olarak bilinmektedir. İkinci tip bağlantıların büyük bir avantajı metalik bağlantılara kıyasla yüksek sertliktir. Diğer taraftan, başarılı bir birleştirme (bağlanma) elde etmek için yapıştırılmış bağlantılara uzun ve yüksek bir basınç uygulanmaktadır. Bu yapıştırıcıların kullanımına ek olarak, uygulama sırasında sağlı ve çevre üzerindeki olumsuz etkileriyle ilgili endişeleri hala bilim adamları tarafından tartışılmaktadır (URL-3). Bununla birlikte birçok çalışmada tutkallı birleştirmelerin mekanik performansları incelenmiştir (Bardak vd., 2017).

Fiziksel ve ekolojik özelliklerini uzun süre sürdürerek, ahşabın boyutsal sınırlarının üstesinden gelmek için, yapıştırıcı kullanılmadan elde edilen sürtünme kaynaklı birleştirmeler, yapıştırılmış birleştirmelere göre daha avantajlı olduğu görülmektedir. Sürtünme kaynağı teknolojileri, bilindiği üzere termoplastik malzemeler ve metaller için kullanılmaktadır. Ahşap Yapı Laboratuvarlarında yapılan araştırmalar 'da (IBOIS), küçük ahşap örnekler ile ilk uygulama 2003-2006 yılları arasında başlanmıştır. Bir ahşap-ahşap birleşimi elde etmek için, iki ahşap plaka arasındaki ara yüz, basınçla birleştirilmiş hızlı ve kısa salınımlı sürtünme hareketi ile ısıtılmaktadır. Isı enerjisi, odun hücre içi bileşiklerinin termal bir şekilde bozulmasına yol açmaktadır. Bu bozulma işleminin kimyasal ürünleri, sürtünme hareketi durduğunda ve ara yüzey soğurken belirli bir soğutma basıncı uygulandığında sertleşen viskoz bir termal olarak yumuşatılmış malzeme tabakası oluşturur ve bu şekilde parçalar birleşmiş olur. Prensip olarak, her türlü ahşap malzeme, kaynak yöntemi ile birleştirilebilmektedir (URL-3). 
Odun kaynak yöntemi, hem ekolojik hem de ekonomik açıdan verimli olduğu anlamına gelen çevre dostu bir teknolojidir. Yapıştırıcısız ahşap kaynağı ile iki farklı üretim sistemi geliştirilmiştir: doğrusal titreşim kaynağı ve yüksek hızlı rotasyon kaynağı (Şekil 2). Titreşim kaynağı, iki düz ahşap yüzeyi birbirine kaynaklamak için kullanılır. Ahşap dübeller ile bu parçaları monte etmek için yüksek hızlı rotasyon kaynağı sistemi kullanılır. Eğer ahşap dübel ile basit bir matkap kullanarak döndürülürse, geleneksel olarak kullanılan marangoz tipi dübellerinden yirmi kat daha sağlam bir şekilde sabitlenebildiği ifade edilmektedir. Kullanılan bu yöntem, herhangi bir tamirci atölyesinde ve birçok küçük ve orta ölçekli işletmelerde uygulanabilir olduğu söylenebilir. $\mathrm{Bu}$ ahşap-ahşap birleşimindeki kaynaklama işlemi, odun yapısındaki amorf hücre birleştirici materyal olan ligninin ve aynı zamanda hemiselülozların bozulmasına ve akmasına neden olmaktadır. Ahşapta kaynaklama işlemi basit bir işlem olarak görülmektedir. Bunun için sadece bir bağlantı malzemesi gereklidir. Tüm işlem sadece birkaç saniye sürmektedir ve ortaya çıkan bağ oldukça kuvvetlidir. Basit bir sistem görünümüne rağmen, ahşap kaynaklama işlemi, fizik ve malzeme biliminin gelişmiş uygulamalarını içermektedir (Vaziri, 2011).

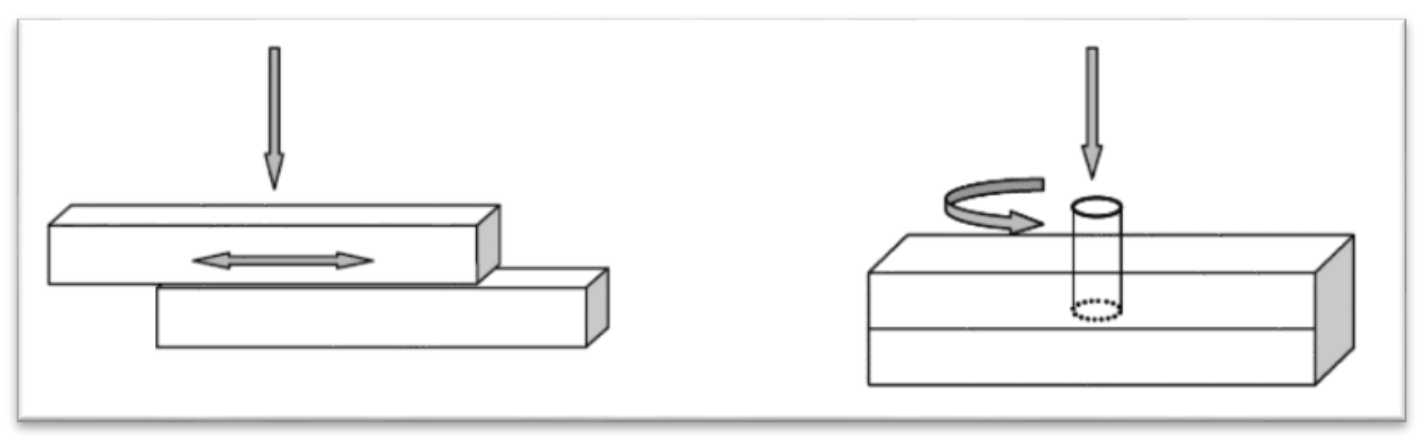

Şekil 2. Doğrusal titreşim kaynağı (solda) ve yüksek hızlı rotasyon kaynağı (sağ) (Vaziri, 2011).

Odun kaynak yöntemi, kerestenin yapıştırıcısız bir şekilde monte edilmesini sağlayan mekanik bir sürtünme işlemidir. İşlem, basınç altında, kaynaklanacak iki ahşap yüzeye alternatif olarak mekanik sürtünme uygulamasından oluşur. Bu işlem, aynı veya farklı ağaç türlerinden kaynaklanan iki düz kereste parçasını kaynaklamak için de uygulanabilir. Buna ek olarak, ayrıca mobilya ve ahşap doğrama üretiminde kullanılabilir. Tek bir dezavantajı olarak, bağlantının dış parça yüzeyleri için değil, yalnızca iç parça yüzeyler için uygun olmasıdır (Şekil 3).
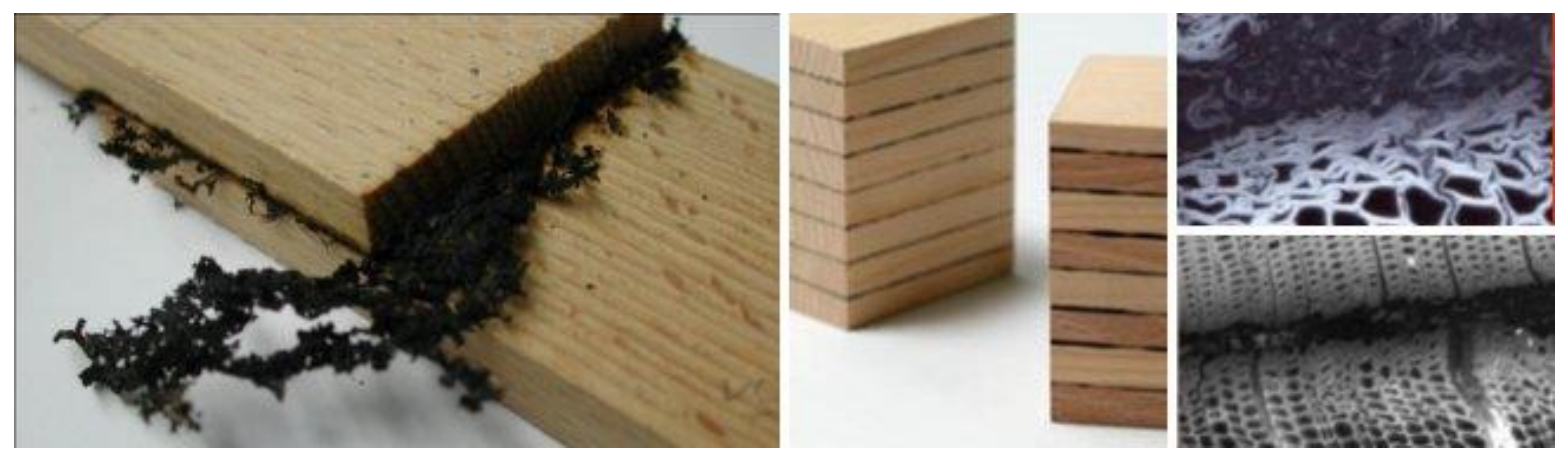

Şekil 3. Sürtünme kaynaklı ahşap birleştirme (URL-3).

Bu kaynak yöntemi ile odun bileşenlerinin özellikle lignin, selüloz ve polyozlar, termoplastik sentetikler gibi polimerik bir yapıya sahiptir. Odun bazlı polimer materyali ile plastik malzeme arasındaki fark, ahşap polimerlerin termal olarak ayrışması ve kaynak işlemi sırasında kimyasal reaksiyonlarla değişmesine rağmen, termoplastikler ise kimyasal bileşimlerine göre aynı kalmaktadır (Stamm vd., 2005a).

Bu metotta yer alan ana kaynak parametreleri, hareket kabiliyeti (WP) ve frekansı (WF), hareket süresi (WT), sürtünme basıncı (HP) ve tutma basıncı süresi (HT)'dir. Bu parametreleri bir yandan, kaynak basıncı, hareketin sıklığı ve genliği gibi makine ayarları ve diğer yandan malzemenin parametreleri (ağaç türleri, yıllık halkaların sıralanışı, rutubet, yoğunluk vs.) gibi ayarlar etkilemektedir (Şekil 4). 


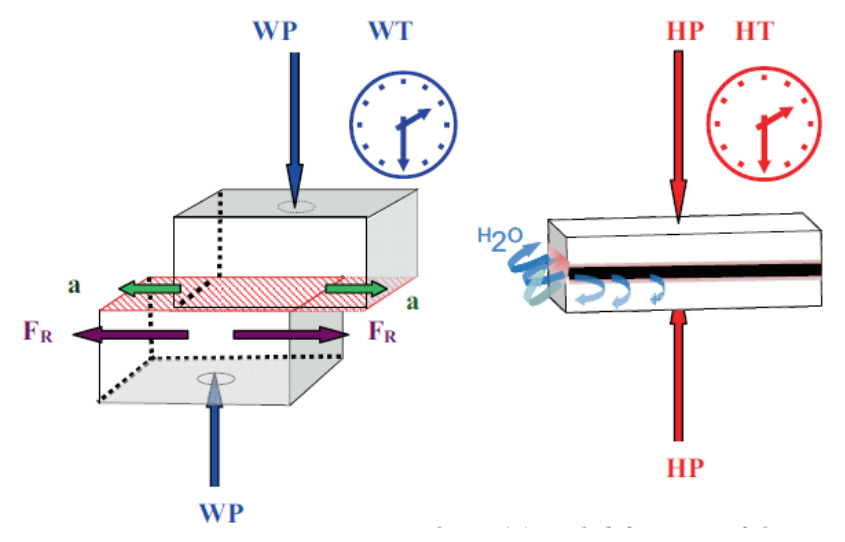

Şekil 4. Kaynaklama işlemindeki kaynak parametreleri (Vaziri, 2011).

Polimer parçalarının bu yöntemdeki işlemleri iki ana kategoriye ayrılır. İlki, mekanik bağlama diğeri ise birleştirmedir. Birleştirme de yapıştırma ve kaynak olarak ikiye ayrılmaktadır. Mekanik bağlama, farklı parçaları mekanik olarak bağlamak için yabancı bir cismin kullanılmasını ifade etmektedir. Mekanik bağlama teknikleri, parçaları bir arada tutmak için harici bağlayıcılar da kullanır. Birleştirme, parçaları yabancı cisimler olmadan daha sağlam sistem üzerine oturtturmaktadır. Yapıştırıcılar, kaynak teknikleri ve solventler, birleştirme işlemlerinin genel örnekleridir. Yapıştırma, bu işlemde kalıcı bir bağlantı oluşturmak için kimyasal reaksiyonlar kullanır. Bağlanma örnekleri arasında bir veya iki parçalı yapıştırıcılar ve çözücüler bulunmaktadır. Kaynak, iki parçayı kimyasal olmayan yollarla birleştirme işlemidir. Bu birleştirmede kullanılan parçanın küçük bir hacminin erimesi gerekmektedir. Malzeme parçalarının birbirine kaynama işlemi için sıcak gazlar, sıcak aletler, ultrasonik titreşimler, sürtünme ve lazerler yaygın olarak kullanılmaktadır.

\section{Ahşap Malzemenin Kaynak Uygulamalarındaki Performansları}

20. yüzyılın sonunda, kaynak teknolojisi önce termoplastik ve sonra metaller için icat edilmiştir. Kaynak teknolojisinin ahşap malzemelere uygulanması hala çok yeni ve bu süreç büyük ölçüde keşfedilmemiş olduğu düşünülmektedir. Kaynak işlemi, kaynaklanmış faz içindeki sıcaklık lignin ve hemiselülozların yumuşamasına ve akmasına neden olduğunda bir dakikadan az bir sürede oluşmaktadır. İşlem, ahşap hücrelerin ayrılmasına ve erimiş bir malzeme matrisine batırılmış bir lif ağının bir oluşumuna yol açmaktadır. Bu durum da kaynağın interfazında belirgin bir iç yapışma sağlamaktadır.

Doğrusal sürtünme kaynağı, son zamanlarda ahşabı birleştirmek için kullanılan otomotiv endüstrilerinde metal ve plastiğin birleştirilmesi için yaygın olarak kullanılan ve herhangi bir yapıştırıcı kullanılmadan elde edilen en yeni bir tekniktir. Bu teknik, herhangi bir sentetik yapıştırıcı veya herhangi bir özel yüzey hazırlığı olmadan kısa bir işlem süresi gerektirir. Ayrıca ahşap yapısına uygun maliyetli bir alternatif olarak görünmektedir (Zhang vd., 2014). Bu daha hızlı üretim sürelerine izin verebileceği için ilgi çekicidir. Odun sürtünme kaynağı yöntemi, yumuşak ağaç ve sert ağaç için ve ayrıca yoğunluğundan dolayı bambu için de kullanılabilir olduğunu kanıtlamıştır (Gfeller vd., 2003; Ganne-Chedeville vd., 2008; Zhang vd., 2017) (Şekil 5 ve Şekil 6.). Bambu odunu; kirişler, paneller, dekoratif malzemeler ve özellikle bambu ürünleri için günlük kullanımda ortak birçok şeyi üretmek için yapıştırma işlemine ihtiyaç duymaktadır (Li vd, 2016a ve 2016b).

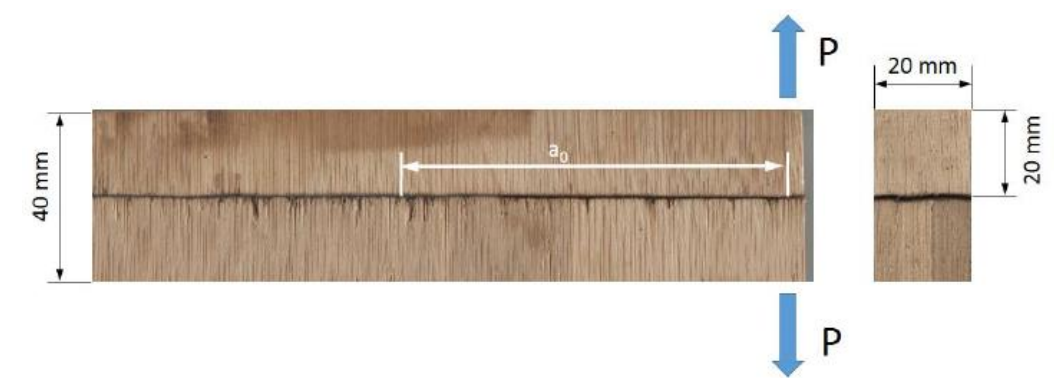

Şekil 5. Konsol kiriş olarak kullanılan Bambu odunun kaynaklanmış hali (Zhang vd., 2017). 


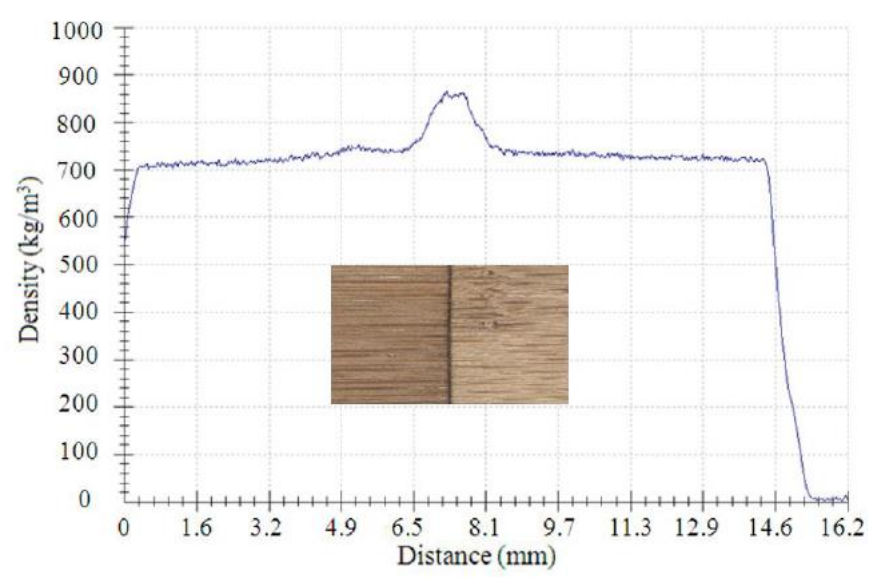

Şekil 6. Uç uca eklenen Bambo ağacının kaynak hattındaki yoğunluk profili (Zhang vd., 2017).

Öncelikle, Sutthoff vd., 1996, Almanya'da ahşabın bir basınç ve sürtünme 1sısı ile birleştirilmesi için girişimlerde bulunmuşlardır. 2000 yılından bu yana, IBOIS ahşap bağlantısı için bu yöntemi araştırmakta ve geliştirmektedir (Gliniorz and Natterer, 2000). İki ahşap malzemeyi birleştirmek için yüksek hızlı rotasyon ile dübel kullanılmış ve sağlam bağlantılar elde edilmiştir. Birleştirilecek ahşap blokların yüzeyine dübel açısı, malzemenin mekanik performansı üzerinde belirgin bir etkiye sahip olduğu bulunmuştur (Bocquet vd., 2007). Kaynak teknolojisi masif ahşap ve ahşap esaslı panelleri (kontrplak, OSB, MDF vb.) başarılı bir şekilde bir araya getirilebildiği ve yapı kullanımı için gerçekleştirilen bağlantıların olumlu yönde sonuçlar sağladığı ifade edilmektedir (Christelle, 2008).

Kaynak parametrelerinin etkisi ve kaynak hattı yoğunluğu önceki çalışmalarda incelenmiştir (Amirou vd., 2016). İğne yapraklı ağaçlardan ladin odunu, kolay hücre duvarlarının çökmesine maruz kalan tek ticari yumuşak ağaçtır ve bu nedenle kaynaklamadaki mekanik davranışı oldukça farklıdır. Kaynaklı birleştirme ile elde edilen parmak dişli Ladin odunu birleştirmelerdeki alın tipi birleştirmedeki kaynak hattının (welded line) su direnci üzerinde etkisi incelenmiştir (Amirou vd., 2017). Sonuç olarak, kaynak basıncı 2.5 MPa'dan 3.75 MPa çıktıkça 6 sn kaynaklama süresinde elde edilen su direnci değeri ciddi oranda artış göstermiştir (Şekil 7).

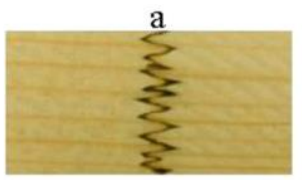

c

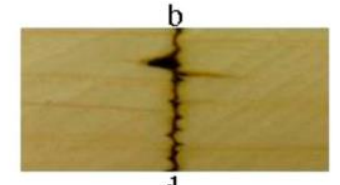

d

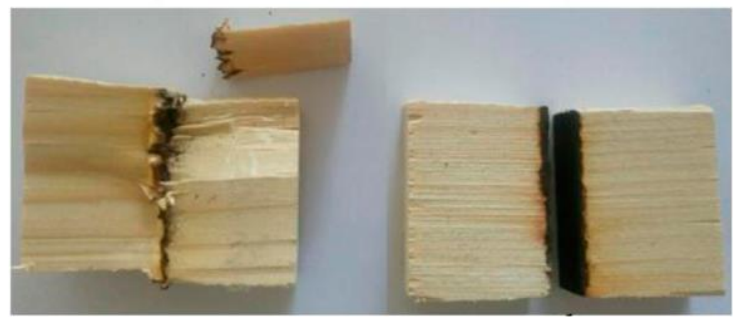

Şekil 7. Makaslama testi sonrası parmak dişli birleştirmeye benzer bir Ladin türünün kaynak hattındaki birleştirmenin durumu (Amirou vd., 2017).

Parmak dişli birleştirmeler, ahşap parçaların her bir ucunda parmak profili işlenerek ve buna uygun bir yapıssal yapıştırıcı kullanılmak şartıyla uzun boyutlu kereste oluşturmak için parçaları belli basınç altında birleştirilmesinden meydana gelmektedir. Bu tip birleştirme, ahşap I-kirişlerinde ve lamine ahşap kiriş (Glulam) gibi birkaç ahşap tasarım ürünü olarak kullanılmaktadır. Bu tür yapısal uygulamalarda, ahşap ve yapıştırılmış bağlantı yerinin, belirtilen servis yüklerini (gerilmeler gibi) taşıyacak kadar güçlü olması beklenmektedir. Prensip olarak, parmak dişli birleştirme işlemi, mukavemet azaltıcı kusurların yok edecek yüksek mühendislik özelliklerine sahip bir ürün üretmek, tutkal bağlantı yeri yüzey alanının artmasını sağlamaktadır. Bağlantının mukavemeti, yoğunluk, doğal kusurlar ve buna bağlı tutkal kullanımı gibi bir takım oduna bağlı faktörler ve makine işleme parametreleri, kereste sıcaklığı ve rutubet içeriği gibi özel işlem parametreleri ile ilişkilendirilmektedir (Bustos vd 2003; Karastergiou and Ntalos, 2005; St-Pierre vd. 2005; Dagenais and 
Salenikovich, 2008; Vassiliou vd., 2009).

Leban vd., 2008, dönme sıklığının Norveç ladinlerinden üretilen kayın kaynaklı dübelinin dönme sıklığı üzerindeki etkisini araştırmıştır. Bunun için $1500 \mathrm{dk}^{-1}$ frekansında $12 \mathrm{~mm}$ çapında bir dübel kullanılmıştır. Sonuç olarak, ortalama, kaynak süresi 4 sn ve kaynak kuvveti olarak 2145 N elde edilmiştir. Kanazawa vd., 2005 kaynak etkisi (kayın dübeli kullanarak) radyal ve teğet yüzeydeki kaynak içi kuvvet üzerindeki etkisini araştırdılar. Analiz edilen tüm kaynak etkilerinde (10, 20 ve $30 \mathrm{~mm})$, teğet yön en iyi araştırma sonuçlarını göstermiştir.

Teknolojiye kolayca uyarlanabilen, gözenekli bir yapı malzemesine sahip olan ağaç malzemenin mühendislik uygulamalarında kolayca uygulanabileceğini ve birleştirmelerin yapısına da oldukça uygun bir şekilde dayanıklılık gösterdiği yapılan çalışmalarda görülmektedir (Vaziri, 2011). Parçaların ara yüzünde meydana gelen sürtünme 1sıs1, malzemenin yoğunluğunda önemli bir rol oynamaktadır (Ganne-Chedeville vd., 2006). Vaziri vd., 2011, kaynaklı bölgede yoğunlaşma derecesi, işlenmemiş odun yoğunluğunun \%160-\%190 arasında değişiklik gösterdiğini ifade etmişlerdir. Daha önceki araştırmalar, odunun kaynak teknolojisinin titreşim kaynaklı sürtünme ve dönme hareketi ile mekanik kaynaklı sürtünme dikkate alınarak gerçekleştirildiğini göstermektedir (Belleville vd., 2011).

Properzi vd., 2005, yapışma hattının direnci, yapışan iki yüzeydeki odunun lif yönünden etkilenmektedir. Örneğin, ahşabın iki yüzeyinin lifleri birbirine paralel olarak uygulandığında, teğet ya da radyal olarak lif dizilişi ile kaynak dayanımı farkı yaklaşık \%10’luk olduğu açıklanmaktadır. Eğer ahşabın lifleri birbirine dik olarak kaynaklama işlemi yapılırsa, birleşme mukavemeti gözle görülür şekilde düşük değer vermektedir. Bunun ile birlikte iki yüzeyin liflerinin birbirine paralel olduğu örneklerde ise, liflerin birbirine dik olarak elde edilen yüzeylerin yaklaşık yarısı kadar değer olduğu gözlemlenmektedir. $\mathrm{Bu}$ farklılıklar, lif-matrix kompozitlerin lif dizilimi homojenliği üzerine etkisi olduğunu ortaya çıkartmaktadır. Dahası, Omrani vd., 2009a çalışmasında bu farklılıkları istatistiksel olarak anlamlı bir şekilde ortaya çıkartmıştır.

Önceki çalışmalarda, kaynak süresi 3 sn'den 6 sn’ye, $100 \mathrm{~Hz}$ ile kaynak frekansı, 3 mm titreşim genliği ve 1.3'ten 2MPa artan kaynak basıncı ile en yüksek ve en az çekme makaslama değişkenleri elde edilmiştir (Gfeller vd., 2003; Ganne-Chédeville vd., 2005). Ladin odununda, 2MPa'dan daha fazla çekme makaslama mukavemeti elde etmişlerdir (Gfeller vd., 2003, 2004). Mansouri vd., 2009, 1.5 sn kaynak süresi, 150Hz frekans ve titreşim genliği $2 \mathrm{~mm}$ olan kaynak birleştirme ile elde edilen kayın odunlarının direnci üzerinde araştırma yapmıştır. Sonuçlara göre, suyun içinde 4 saatten fazla kaldığında, direnci belirgin bir şekilde azalma gösterdiğini vurgulamıştır. Mansouri vd., 2011 bir başka çalışmasında, yüksek kalitedeki çam odunlarının kaynaklama işlemindeki mukavemeti; diri odunu için, 3.5 MPa, öz odun için 4.1 MPa olarak ortalama değerler elde edilmiştir. Vaziri vd., 2012 çam odunu ile 2.0 sn'den 2.8 sn'ye olan kaynak süresini 3.5 sn'ye kadar uzattığında daha iyi çekme-makaslama direnci elde ettiğini açıklamışlardır. Yine Mansouiri vd., 2011 çalışmasında, çam odunlarını 20 gün su içinde bekleterek, kaynak hattının ulaşamadığı bölgelerdeki kaynak hattını çevreleyen odun parlaklığını görüntülemişlerdir. 3 örnek arasındaki renk farklılığının, kaynak parametrelerinin farklılığından kaynaklanmadığını, sadece örneğin içinde doğal olarak bulunan erimiş reçine miktarından kaynakladığını ifade etmişlerdir (Şekil 8).

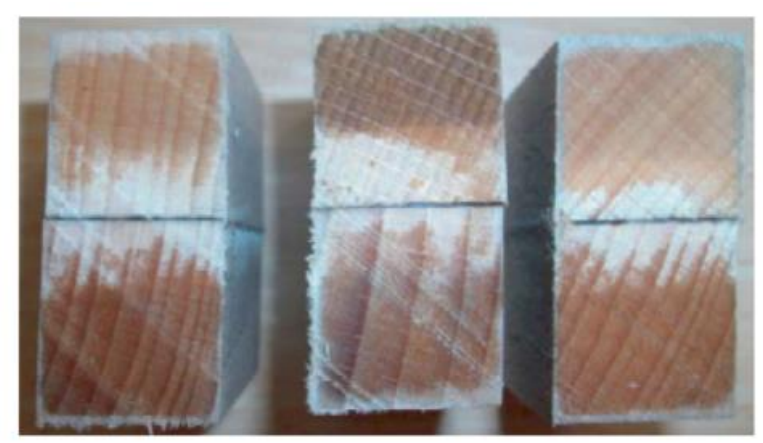

Şekil 8. Kaynaklanan sarıçam odunlarının suda beklenmiş görüntüleri (Mansouiri vd., 2011).

Kaynak yöntemi ile elde edilen ahşabın endüstriyel uygulaması, düşük rutubet direncinden dolayı iç mekân kullanımıyla sınırlıdır. Malzemeler, özellikle düşük mukavemetlerinin yapısal kullanıma uygun olmasına rağmen, mobilya gibi iç mekân uygulamaları için de uygundur. Su geçirmez kimyasalların kullanımı olmadan, iyi bir birleştirme için bu kimyasallar ya da metalik araçların kullanılmaması araştırmacıları cezbetmiştir. 
Çünkü bunların kullanımı bu tür kaynaklı bağlantıların çevre dostu özelliğini bozacaktır (Pizzi vd., 2004; Omrani vd., 2009b).

Farklı rutubet altında odun birleşiminde oluşan açılmalar (kötü birleşme), bir yandan şişme ve büzülme sırasında oluşan deformasyonlara diğer yandan sürtünme kaynak birleştirmeli malzeme özelliklerine bağlıdır (Şekil 9). Zor vd., 2019 hazırlamış olduğu ön pilot deneme çalışmasında, sarıçam odunları ile hazırlanan kaynak birleştirmelerdeki odunların rutubet farkından dolayı kaynak hattının tam birleşmediğini (\%13-14 rutubet altında), uygun rutubetleri tespit ettikten sonra (\%10-11 rutubet altında), çalışmanın deney kısımlarına geçtiklerini ifade etmişlerdir. Vaziri vd., 2010 çalışmasında, kaynak birleştirme makinesi ayarı ve ahşap malzeme parametreleri, kaynak yeri kırılma şekli ve yerinden dolayı birleştirilen malzemelerinin özellikleri üzerinde önemli etkileri olduğunu göstermiştir.
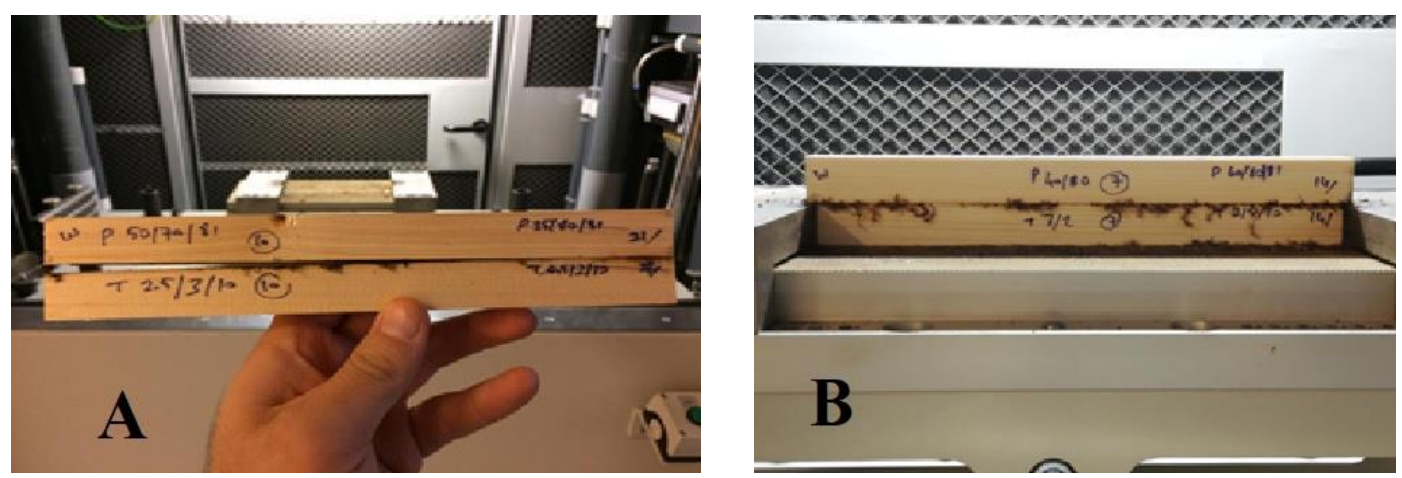

Şekil 9. \%13-14 rutubetteki çam odunun kaynaklama sonrası kötü bir birleşme görüntüsü (A), \%10-11 rutubetteki çam odunun kaynaklama sonrası iyi bir birleşme görüntüsü (B) (Zor vd., 2019).

Mekanik bağlantı yöntemleri, gerilme konsantrasyonu, galvanik korozyon ve ısıl genleşme katsayısında uyumsuzluk ve delme işlemi ile ortaya çıkan güçlendirici liflere hasarı gibi problemlere sahiptir. Termoplastik kompozitlerde kaynaklama veya füzyon yapıştırma bu problemleri büyük ölçüde ortadan kaldırabilmektedir (Maguire, 1989). Her ne kadar bazı araştırmacilar (Eveno and Gillespie, 1988; Hou and Friedrich 1992) kompozitlerin direnç kaynağı üzerinde çalışmış olsalar da, proses parametreleri ve bağlantı kuvvetleri üzerindeki etkileri ile ilgili yeterli literatür mevcut değildir. Sürtünme kaynağı yöntemlerinin teknik amacı, yüzey sürtünmesinin ürettiği 1sıdır; bu durum, malzemenin moleküler yapısında yoğun harekete neden olmaktadır. Bundan dolayı malzemeler kaynak yapmaya uygun bir duruma gelmektedir (Crawford and Tam, 1981). Üstün mukavemet ve sertlik/ağırlık oranı sayesinde, kompozit malzemeler havacılık, ulaştırma ve denizcilik gibi yüksek teknoloji uygulamalarında kullanılmaktadır (Chawla, 1998). Geri dönüştürülebilir ve yeniden şekillendirilebilir niteliklerinden dolayı, termoplastik kompozitler çevreye zarar vermeyen uygulamalar için tercih edilmektedir (Benatar and Gutowski, 1986; Todd, 1990; Stokes, 1989; Wedgewood and Hardy, 1996).

Sürtünme karıştırma kaynağı, farklı davranışlar arasındaki karmaşık etkileşimleri içeren ve kaynak bölgelerinde değişen termo-mekanik bir işlemdir (Nandan vd., 2008; Ageorges vd., 2001; Czigany and Kiss, 2005; Mishra and Mahoney, 2007; Krishnan, 2002). Mendes vd., 2014. ABS (Akrilonitril butadiyen stiren) levha kaynaklarının kalitesinın sürtünme karıştırma kaynağı (FSW) 'nın ana parametreleri olan dönme hızı, hareket hızı ve eksenel kuvvet üzerine etkisini incelemişlerdir. Sabit bir omuza sahip olan ve harici 1sıtma sistemine sahip olmayan bir alet kullandılar. Dönüş hızı ve eksenel kuvveti belirli bir sınırın üstünde olduğunda, dışardan ısıya gerek duymadan, başarılı bir kaynaklama işlemine ulaşıldığı sonucuna varmıştır.

Yapılan araştırmalara göre, farklı uygulamalarda kullanılan sürtünme kaynak birleştirme yöntemin ahşap için de olumlu yönde olduğunu göstermiştir. İşlem, herhangi bir ek malzeme gerektirmediği için sürtünme 1sıs1 nedeniyle yüzeyler yaklaşık $420-450^{\circ} \mathrm{C}$ 'de 1 sınmaktadır (Stamm, vd., 2005a). Ahşabın yüksek sıcaklık bağlantılarında, farklı ahşap bileşenlerinin (selüloz, hemiselüloz, lignin) 1sıl dönüşüm üzerine etkisi esas alınmaktadır (Stamm vd., 2005).

\section{Sonuç ve Öneriler}

Özellikle son yıllarda mühendisliğin birçok uygulamalarında yerini alan sürtünme kaynak metodu, ahşap veya ahşap olmayan malzemeleri birbirine mekanik yollarla birleştirme işlemi yaygın olarak kullanılmaktadır. Bilim 
adamları, özellikle ekolojiye alternatif olarak düşündükleri bu yöntemi, küçük ve büyük boyutlu malzemeler için kullanımda uygulama alanları geliştirmektedir. Bunun için yapılan bu tekniğin çok yeni olduğu iyi bilinmektedir. Bilim adamları tarafından, her biri benzersiz avantajlara sahip birçok kaynak yöntemi geliştirilmiştir. Kaynaklı bağlantılar çeşitli malzemelerden, geometrilerden ve boyutlardan yapılabilmektedir. Eğer uyumlularsa, birbirine benzemeyen malzemeler birleştirilebilir. Bununla birlikte, kaynak işleminin mekaniği, malzeme yapısı üzerindeki etkileri ile birlikte hala büyük ölçüde bilinmemektedir. Ancak yakın zamana kadar, ahşap kaynaklı bağlantıların özellikle su geçirmezlik ve çekme-makaslama mukavemeti konusunda yoğun çalışmalar yapıldığı görülmektedir. Bu yöntem gerçekten başarılı sonuçlar gösterirse, orman ürünleri endüstrisinin geleceğini önemli ölçüde değiştireceği tartışlmaz bir gerçektir.

\section{Teşekkür}

Bu çalışma, TÜBİTAK BIDEB-2219/2019 kodlu 1059B191800412 nolu projesi tarafindan desteklenmiştir.

\section{Kaynaklar}

1. Ageorges, C., Ye L. and Hou, M. (2001). Advances in fusion bonding techniques for joining thermoplastic matrix composites: a review', Composites A, 2001, 32A, 839-857.

2. Amirou, S, Pizzi A., Luo, H. (2016). Variation of shear properties of welded spruce at different pressures and welding times. Biotribology. 5:61-66.

3. Amirou, S., Pizzi,. A., Belleville, B., Delmotte, L. (2017). Water resistance of natural joint of spruce produced by linear friction welding without any treatment, International Wood Products Journal, 8(4), 201-207.

4. Bardak, T., Tankut, A.N., Tankut, N., Aydemir, D., Sözen, E. (2017). The Bending and Tension Strength of T-Type Mortise and Tenon Joints Bonded with Polyvinyl Acetate Nanocomposites. Maderas: Ciencia y Tecnología 19(1):51 - 62.

5. Belleville, B., Segovia, C., Pizzi, A., Stevanovic, T., Cloutier, A. (2011). Wood blockboards fabricated by rotational dowel welding. Journal of adhesion science and technology 25, 2745-2753.

6. Benatar, A.,Gutowski, T. G. (1986). Methods for fusion bonding thermoplastic composites', SAMPE Q., 1986, 18(1), 35-42.

7. Bocquet, F. A., Pizzi, A., Despres, H. R., Mansouri, L., Resch, D., Michel and Letort F. (2007). Wood joints and laminated wood beams assembled by mechanically-welded wood dowels. J. Adhesion Sci. Technol. 21, 301-317.

8. Bustos, C., Mohammad, M., Hernández, R.E., Beauregard, R. (2003a). Effects of curing time and end-pressure on the tensile strength of finger-joined black spruce lumber. Forest Prod. J. 53 (11-12): 8589.

9. Chawla, K.K. (1998). Composite materials, science and engineering';1998, New York, Springer-Verlag.

10. Christelle, G.C. (2008). Soudage linéaire du bois: étude et compréhension des modifications physicochimiques et développement d'une technologie d'assemblage innovante. Faculté des Sciences et Techniques Nancy, Doctoral Thesis.

11. Crawford, R. J.,Tam, Y. (1980). Friction welding of plastics. J. Mater. Sci., 16, 3275-3282.

12. Czigany T. and Kiss Z. (2005). 'Friction stir welding of fiber reinforced polymer composites', Proc. 18th International Conferences on Composite Materials. Jeju Island, Korea, August 2005.

13. Dagenais, C., Salenikovich, A. (2008). Influence of machining parameters on the tensile strength of finger-jointed sugar maple lumber. Wood Fiber Sci. 41(1):55-61.

14. Eveno, E. C., Gillespie, J. W. (1988). An experimental investigation: resistance welding of graphite polyetheretherketone composites. J. Thermoplast. Compos., 1, 322-337.

15. Ganne-Chedeville, C., Duchanois, G., Pizzi, A., Leban, J. M,.Pichelin, F. (2008). Predicting the thermal behaviour of wood during linear welding using the finite element method. J.Adhesion Sci.Technol., 22:1209-1221.

16. Ganne-Chedeville, C., Leban, J-M., Properzi, M., Pichelin, F., Pizzi, A. (2006). Temperature and density distribution in mechanical vibration wood welding. Wood Sci Technol, 40:72-76.

17. Ganne-Chedeville, C., Pizzi, A., Thomas, A., Leban, J. M., Bocquet, J. F., Depres, A.,Mansouri, H. R. (2005). Parameter interactions, two-block welding and the wood nail concept in wood dowels welding. Journal of Adhesion Science and Technology, 19, 1157-1174

18. Gfeller, B., Pizzi, A., Zanetti, M., Properzi, M., Pichelin, F., Lehmann, M., Delmotte, L. (2004). Solid wood joints by in stir welding of structural wood constituents. Holzforschung 58(1):45-52. 
19. Gfeller, B., Zanetti, M., Properzi, M., Pizzi, A., Pichelin, F., Lehmann, M., Delmotte, L. (2003). Wood bonding by vibrational welding. J Adhes Sci Technol 17:1425-1590.

20. Gliniorz, K. U., Natterer, J. (2000). Holzschweißen - Innovative Verbindungstechnologien im Holzbau, Tagungsunterlagen, Symposium der Lignaplus/Weltmesse für die Forst- und Holzwirtschaft in Hannover/D, Mai 21-25, 79-83.

21. Hou, M., Friedrich, K. (1992). Resistance welding of continuous glass fiber reinforced polypropylene composites'. Compos. Manuf., 3(2), 153-163.

22. Kanazawa, Pizzi, A., Properzi, M., Delmotte, L., Pichelin, F. (2005). Parameters influencing wooddowel welding by high-speed rotation. J. Adhesion Sci. Technol., 19 (12): 1025-1038.

23. Karastergiou, S., Ntalos, G. (2005). Bending strength properties of scarf jointed European spruce wood (Picea excelsa). Proceedings of International Scientific Conference Engineering Design Interior and furniture design. Oct. 15-17, Sofia, Bulgaria

24. Krishnan, K. N. (2002). On the formation of onion rings in friction stir welds. Mater. Sci. Eng., 2002, 327, 246-251.

25. Li, H., Zhang, Q., Wu, G., Xiong, X.,and Li, Y., (2016). A review on development of laminated bamboo lumber. Journal of Forestry Engineering 1(6), 10-16.

26. Li, Y., Xu, B.,., and Jiang, S. (2016). Present situation and the countermeasure analysis of bamboo processing industry in China. Journal of forestry Engineering 1(1).2-7

27. Maguire, D. M. (1989). Joining thermoplastic composites', SAMPE J., 1989, 25, (1), 11-14.

28. Mansouri, H. R., Omrani, P., Pizzi, A. (2009). Improving the water resistance of linear bibration welded wood joints., J. Adhesion Sci. Technol. 23, 63-70.

29. Mansouri, H. R., Pizzi, A., Leban, J. M., Delmotte, L., Lindgren, O., Vaziri, M. (2011). Causes for the improved water resistance in pine wood linear welded joints. J Adhes Sci Technol. 25:1987-1995.

30. Mendes, N., Loureiro, A., Martins, C., Neto, P.,Pires, J. N. (2014). Effect of friction stir welding parameters on morphology and strength on acrylonitrile butadiene styrene plate welds, Mater. Des., 2014, 58, 4572-4464.

31. Mishra, R.,Mahoney, M. (2007). Friction stir welding and processing, Materials Park, OH, ASM International.

32. Nandan, R., Debroy, T.,Bhadeshia, H. (2008). Recent advances in friction stir welding-process, weldment structures and properties', Prog. Mater. Sci., 2008, 53, 980-1023.

33. Omrani, P, Mansouri, H.R., Duchanois, G., Pizzi, A. (2009a). Fracture mechanics of linearly welded wood joints: effect of wood species and grain orientation. J Adhes Sci Technol. 23:2057-2072.

34. Omrani, P., Mansouri, H. R., Pizzi, A. (2009b). Influence of grain direction and preheating on linear wood welding. Eur J Wood Prod 68(1):113-114.

35. Pizzi, A., Leban, J-M, Kanazawa. F, Properzi. M, Pichelin. F, (2004). Wood dowels bonding by high speed rotation welding. J Adhes Sci Technol 18:1263-1278.

36. Properzi, M., Leban, J. M., Pizzi, A., Wieland, S., Pichelin, F., Lehmann, M. (2005). Influence of grain direction in vibrational wood welding, Holzforschung 59(1), 23-27. DOI: 10.1515/HF.2005.004.

37. Stamm, B., Natterer, J., Navi, P. (2005a). Joining wood by friction welding. Holz als Roh-und Werkstoff, 313-320.

38. Stamm, B., Windeisen, E., Natterer, J., Wegener, G. (2005). Thermal behaviour of polysaccharides in wood during friction welding, Holz Roh Werkstoff 63, 388-389.

39. Stokes, V. K. (1989). Joining methods for plastics and plastic composites:an overview. Polym. Eng. Sci., 1989, 29, (19), 1310-1324.

40. St-Pierre, B., Beauregard, R., Mohammad, M., Bustos, C. (2005). Effect of moisture content and temperature on the tension strength of finger jointed black spruce lumber. Forest Prod. J. 55(12): 9-16.

41. Sutthoff, B., Franz, U., Hentschel, H., Schaaf, A. (1996). Verfahren zum reibschweissartigen Fügen und Verbinden von Holz. Patent DE 19620273 C2.Deutsches Patent- und Markenamt.

42. Todd, S. M. (1990). Joining thermoplastic composites', Proc. 22nd Int. SAMPE Technical Conf., Boston, MA, USA, November 1990, Society for the Advancement of Material and Process Engineering, 383-392.

43. URL-1: (https://nptel.ac.in/courses/107103012/module6/lec1.pdf)

44. URL-2: (https://me-mechanicalengineering.com/advantages-and-disadvantages-of-welded-joints-overriveted-joints/)

45. URL-3; https://www.epfl.ch/labs/ibois/page-18295-en-html/page-137287-en-html/page-20697-en-html/

46. Vassiliou, V., Barboutis, I., Ajdinaj, D., Thoma, H. (2009). PVAc Bonding of finger jointed Beech wood originated from Albania and Greece. Proceedings of International Conference Wood Science and Engineering in the third millennium, ICWSE.715. Transilvania. University of Brasov, Romania.721 p.

47. Vaziri, M. (2011). Water Resistance of Scots Pine Joints Produced by Linear Friction Welding, Luleå University of Technology, Doctoral Thesis. 
48. Vaziri, M., Lindgren, O., Pizzi, A., Mansouri, H. R. (2010). Moisture sensitivity of Scots pine joints produced by linear frictional welding. J. Adhesion Sci. Technol. 24, 1515-1527.

49. Wedgewood, R., Hardy, P. E. (1996). Induction welding of thermoset composite adherents using thermoplastic interlayer and susceptors', Proc. 28th Int. SAMPE Technical Conf., Seattle, WA, USA, November 1996, Society for the Advancement of Material and Process Engineering, 850-861.

50. Zhang, H., Pizzi, A., Lu, X., Zhou, X. (2014). Optimization of tensile shear strength of linear mechanically welded outer-to-inner flattened moso bamboo. BioResoruces, 9(2), 2500-2508.

51. Zhang, H., Pizzi, A., Lu, X., Wang, Z. (2017). Study of end-grain butt joints obtained by friction welding of Moso bamboo. BioResources, 12(3), 6446-6457.

52.Zor, M., Vaziri, M., Sandberg D. (2019). The effect of heat treatment on tension strength and water resistance of pine wood produced by linear friction welded (in review). 